\title{
O agente comunitário de saúde e suas práticas educativas em saúde bucal: uma avaliação qualiquantitativa
}

\author{
Community health agents and their educational practices \\ in oral health: a qualitative/quantitative evaluation
}

Fábio Luiz Mialhe ${ }^{1}$

Fernando Lefèvre ${ }^{2}$

Ana Maria Cavalcanti Lefèvre ${ }^{3}$

${ }^{1}$ Faculdade de Odontologia de Piracicaba, UNICAMP. Av. Limeira 901, Caixa Postal 52. 13414-903 Piracicaba SP. mialhe@fop.unicamp.br ${ }^{2}$ Departamento de Prática de Saúde Pública, Faculdade de Saúde Pública (FSP),

Universidade de São Paulo (USP)

${ }^{3}$ Instituto de Pesquisa do

Discurso do Sujeito

Coletivo (IPDSC\}

\begin{abstract}
Among the activities performed by the community health agent (CHA), the educational actions are of fundamental importance for the provision of healthcare. Therefore, the scope of this study was to evaluate these aspects in a random sample of 80 CHAs, drawn from 16 Family Health Program Units in Piracicaba, São Paulo State, representing $51.3 \%$ of the population stud$i e d$. The data was collected through semi-structured interviews, which were recorded and transcribed, using a script with questions about dental health education practices conducted by the agents. For the data analysis, the answer processing technique of the Collective Subject Discourse (CSD) was used. It was established that dental health education activities are performed sporadically by CHAs and addressed mainly to pregnant women, mothers and children, in a vertical model of information transmission, seeking changes in individual behavior and the incorporation of healthy habits. The results suggest the need of CHAs to rethink the way they are developing their educational practices in dental health. However, for this to become a reality, it is indispensable to count on the support of the health manager in processes of permanent education directed to these professionals and to the whole team.
\end{abstract}

Key words Health education, Community Health Agent, Family Health Program
Resumo Dentre as atividades desenvolvidas pelos agentes comunitários de saúde (ACS), as ações educativas são fundamentais para a produção do cuidado. O objetivo deste estudo foi avaliar esses aspectos em uma amostra aleatória de $80 \mathrm{ACS}$, provenientes de 16 Unidades de Saúde da Família do município de Piracicaba, SP, representando de 51,3\% da população estudada. Os dados foram coletados por meio de entrevistas semiestruturadas, seguindo um roteiro com temas pertinentes às práticas educativas em saúde bucal dos agentes, as quais foram gravadas e posteriormente transcritas. Para a análise dos dados, utilizou-se a técnica de processamento de respostas do Discurso do Sujeito Coletivo (DSC). Verificou-se que as atividades educativas em saúde bucal são realizadas de forma esporádica e voltadas prioritariamente às gestantes, mães e crianças, em um modelo vertical de transmissão de informações, visando mudanças de comportamentos individuais e incorporação de hábitos saudáveis. Os resultados sugerem a necessidade dos ACS repensarem a forma como vêm desenvolvendo suas práticas educativas em saúde bucal. Entretanto, para que isso se torne realidade, é imprescindível o apoio e o incentivo do gestor de saúde em processos de educação permanente voltados a estes profissionais e toda a equipe.

Palavras-chave Educação em saúde bucal, Agentes Comunitários de Saúde, Programa Saúde da Família 


\section{Introdução}

A atual política de atenção primária à saúde no país é baseada, em grande parte, na Estratégia da Saúde da Família, obedecendo aos preceitos do Sistema Único de Saúde ${ }^{1-3}$. Para o Ministério da Saúde ${ }^{3}$, a estratégia tem como objetivo "substituir ou converter o modelo tradicional de assistência à saúde, historicamente caracterizado como atendimento da demanda espontânea, eminentemente curativo, hospitalocêntrico, de alto custo, sem instituir redes hierarquizadas por complexidade, com baixa resolutividade e, no qual, a equipe de saúde não estabelece vínculos de cooperação e corresponsabilidade com a comunidade".

Inicialmente, os incentivos federais para as equipes da Saúde da Família eram destinados apenas à formação das equipes mínimas, compostas por um médico generalista ou médico da família, um enfermeiro, um ou dois auxiliares/ técnicos de enfermagem e quatro a seis agentes comunitários de saúde (ACS) ${ }^{3}$. Identificando a necessidade de ampliar o acesso da população brasileira às ações de saúde bucal, o Ministério da Saúde lança a Portaria GM/MS no 1.444, de 28 de dezembro de $2000^{4}$, a qual regulamenta e estabelece incentivo financeiro para a reorganização da atenção à saúde bucal prestada nos municípios. A partir deste momento, as Equipes de Saúde Bucal (ESB) também passaram a fazer parte da estratégia do $\mathrm{PSF}^{4}$.

A implementação das ESB trouxe consigo novas atribuições aos ACS. Compreendendo a saúde bucal como componente da Saúde, em sua expressão mais ampla, Souza et al. ${ }^{5}$ apontaram os ACS como facilitadores do processo de desenvolvimento das ações em Saúde bucal, dentre as quais se destacam as atividades educativas.

As Diretrizes da Política Nacional de Saúde Bucal $^{6}$ também destacam que, dentre as ações de Promoção e de Proteção da Saúde, a Educação em Saúde é uma importante estratégia para reduzir riscos em saúde bucal. Assim, o Documento esclarece que "estas atividades podem ser desenvolvidas pelo cirurgião-dentista (CD), técnico em higiene dental (THD), auxiliar de consultório dentário (ACD) e agente comunitário de saúde (ACS), especialmente durante as visitas domiciliares. As escolas, creches, asilos e espaços institucionais são locais preferenciais para este tipo de ação, não excluindo qualquer outro espaço onde os profissionais de saúde, enquanto cuidadores, possam exercer atividades que estimulem a reflexão para maior consciência sanitária e apropriação da informação necessária ao autocuidado". Apesar de constantes no texto ori- ginal das Diretrizes, atualmente as siglas THD e ACD foram substituídas por TSB (Técnico em Saúde Bucal) e ASB (Auxiliar em Saúde Bucal).

Alguns estudos, como o de Frazão e Marques $^{7}$, verificaram que os ACS, quando devidamente capacitados, podem influenciar mudanças positivas nos conhecimentos em saúde bucal da população sob seus cuidados.

Entretanto, apesar de uma reorientação crescente no campo das reflexões teóricas e metodológicas da Educação em Saúde, verifica-se que ela ainda é majoritariamente desenvolvida pela equipe de forma normativa e biologicista, reproduzindo, de forma acrítica, os conceitos da medicina científica, os quais, muitas vezes, são totalmente descontextualizados da realidade vivenciada pelos agentes ${ }^{8}$.

Diante do exposto e a partir do reduzido número de trabalhos analisando esses aspectos, o objetivo do presente estudo foi avaliar como se dão as práticas educativas em saúde bucal, no trabalho cotidiano do agente comunitário de saúde.

\section{Material e Métodos}

O presente estudo, de caráter qualitativo, exploratório e descritivo, foi realizado no município de Piracicaba, distante $165 \mathrm{~km}$ da capital São Paulo, com uma área territorial total de $1.370 \mathrm{~km}^{2} \mathrm{e}$ população estimada em 358.108 habitantes, concentrando-se $95 \%$ na área urbana ${ }^{9}$.

A pesquisa teve início somente após anuência da Secretaria Municipal de Saúde e aprovação pelo Comitê de Ética em Pesquisa da Faculdade de Odontologia de Piracicaba, da Universidade de Campinas.

A amostra probabilística foi composta por 80 ACS, representando $51,3 \%$ da população de 158 agentes em exercício no município naquele momento, os quais eram provenientes de 16 Unidades de Saúde da Família (USF), das 30 existentes do município, selecionadas aleatoriamente.

Os dados foram coletados por meio de entrevistas semiestruturadas e por um único pesquisador, entre o período de fevereiro e junho de 2008, seguindo um roteiro apresentando as seguintes questões: 1) Nas suas atividades diárias, você trabalha educação em saúde bucal com as pessoas? Fale um pouco mais para a gente. 2) Você teve algum curso ou treinamento que lhe ensinou como fazer atividades educativas em Saúde Bucal?

As mesmas foram realizadas individualmente e em ambiente silencioso e privativo dentro das USF. As conversas foram gravadas em aparelho digital portátil e posteriormente transcritas. 
Os dados foram analisados com base na teoria do Discurso do Sujeito Coletivo (DSC). Segundo Lefèvre e Lefèvre ${ }^{10}$, o DSC caracteriza-se como uma proposta de organização e de tabulação de dados qualitativos, extraindo-se, de cada um dos depoimentos, as Ideias Centrais e/ou as Ancoragens e as correspondentes ExpressõesChave. Com as Expressões-Chave das Ideias Centrais semelhantes, compõem-se um ou vários discursos-síntese na primeira pessoa do singular ${ }^{10}$.

Assim, o DSC expressa a opinião ou o pensamento coletivo, considerando-se a opinião coletiva como fato empírico Nota-se, no entanto, que o DSC não pretende apreender toda representação social, mas, sim, apenas uma de suas camadas, à qual outras camadas podem ser agregadas ${ }^{11}$. Consiste na unificação e no agrupamento de vários sujeitos emissores de discurso, permitindo, em tese, que se coletivizem seus discursos, expressando diretamente a representação social de um dado sujeito social na primeira pessoa do singular, já que se acredita ser este (o "coletivo internalizado") o regime natural de funcionamento das opiniões ou representações sociais ${ }^{10-12}$.

\section{Resultados}

Dentre os ACS entrevistados, 5 (12,5\%) eram do gênero masculino. Quanto à faixa etária, 73,7\% tinham entre 20 e 40 anos, com média de idade de 26,7 anos e 55\% apresentavam entre 1 a 3 anos de exercício da profissão. Em relação à escolaridade, $83,8 \%$ apresentavam o ensino médio completo.

Referente à primeira questão, "Nas suas atividades diárias, você trabalha educação em saúde bucal com as pessoas? Fale um pouco mais para a gente", o Quadro 1 apresenta os dados quantitativos, a partir da síntese da ideias centrais e suas respectivas frequências de manifestações. Verificouse que a ideia mais compartilhada entre os entrevistados foi o da prática educativa voltada para gestantes, crianças, (ideia central $\mathrm{N}$ ) presente em $30 \%$ dos entrevistados e em segundo lugar a ideia central E (Às vezes. Mais voltado para a saúde bucal da criança), presente em $20 \%$ deles.

DSC da ideia central N da questão 01 (Trabalha mais voltado às gestantes, crianças e mães).

"Nas visitas a gente sempre orienta a mãe e a criançada. A mãe, eu já costumo falar desde a ges-

Tabela 1. Síntese das idéias centrais e respectiva frequência de manifestações para a primeira questão: 1) "Nas suas atividades diárias, você trabalha educação em saúde bucal com as pessoas? Fale um pouco mais para a gente."

\begin{tabular}{|c|c|c|}
\hline Idéias Centrais & n & $\%$ \\
\hline A Não, pois tem outros assuntos para trabalhar, outras prioridades ou falta de tempo para isso & 9 & 11,25 \\
\hline $\begin{array}{l}\text { B Não, pois não foi capacitado ou orientado para este tipo de atividade ou porque nunca foi } \\
\text { falado para fazer }\end{array}$ & 10 & 12,5 \\
\hline C Não. O máximo que faz é encaminhar para o tratamento curativo & 4 & \\
\hline $\begin{array}{l}\text { D Não, pois se toca no assunto, vem a cobrança em relação à necessidade de tratamento } \\
\text { curativo }\end{array}$ & 5 & 6,25 \\
\hline E Às vezes. Mais voltado para a saúde bucal da criança & 16 & 20 \\
\hline F Às vezes. Mais voltado para os cuidados bucais do bebê & 8 & 10 \\
\hline G Às vezes, pois não foi orientado ou sabe bem pouco à respeito. & 6 & 7,5 \\
\hline $\begin{array}{l}\text { H Às vezes. Tem dificuldade em trabalhar o assunto pois não sabe o quê fazer, para onde } \\
\text { encaminhar os casos que necessitam de tratamento curativo, pois o acesso gratuito ao CD é } \\
\text { difícil }\end{array}$ & 5 & 6,25 \\
\hline I Às vezes, pois dependendo da casa onde faz a visita, nem todos aceitam falar de higiene & 2 & 2,5 \\
\hline J Muito pouco. Geralmente em parceria com outros profissionais & 5 & 6,25 \\
\hline $\mathrm{K}$ Trabalha às vezes. Mais quando percebe a necessidade de tratamento & 6 & 7,5 \\
\hline L De vez em quando. Mais quando eles perguntam. & 7 & 8,75 \\
\hline M Trabalha com educação em saúde bucal mais dentro da escola & 14 & \\
\hline N Trabalha mais voltado às gestantes, crianças e mães & 24 & 30 \\
\hline O Tem de ter jeito para falar sobre o assunto, de acordo com a realidade deles & 2 & 2,5 \\
\hline P Orienta sobre o câncer bucal. & 2 & 2,5 \\
\hline $\begin{array}{l}\text { Q Com adultos trabalha mais no sentido de orientá-los a procurar por tratamento do tipo } \\
\text { curativo }\end{array}$ & 4 & 5 \\
\hline $\mathrm{R}$ Trabalha, mas muitas vezes as pessoas não têm condições de seguir as orientações & 2 & 2,5 \\
\hline S Alguns só querem saber da parte curativa & 1 & 1,25 \\
\hline
\end{tabular}

Obs: a soma da freqüência de idéias centrais extrapola o número de 80 respostas e a porcentagem de $100 \%$, pois um mesmo indivíduo poderia apresentar mais de uma idéia central. 
tante os cuidados dos dentes, porque o risco de cárie é maior. Tá pegando desde aquela mãe que você já foi quando era gestante e você falou sobre tomar cuidado com a dentição por causa que pode cair, aquela coisa; se tiver algum problema que é normal, aquela coisa toda. E depois, quando essa criança nasce, a gente faz as 'visita', vai lá, e pergunta se ela acha que tem que escovar o dentinho da criança, se tem que escovar a boquinha. Muitas falam que não porque não tem nem dentes, né? Aí a gente explica de tá limpando com a fraldinha dentro da boquinha, passando uma "gazinha", já assim, na gengivinha, para ir acostumando. Depois a gente tem aquelas escovinhas assim, pequenininha que é de bebezinho que é para o nenê já ir acostumando a por na boquinha assim, pra não pegar uma certa idade e já não estranhar, assim, a escova. Daí a gente fala: “-O bebê já tá escovando? Mãe, como que é?” Porque às vezes a mãe mesmo não escova. Sempre mais com as mães eu faço. Aí começa, desde bebê, a fazer a orientação de escovar dentes, principalmente assim, em questão de criança de 2, 3 anos, que não gosta de escovar o dente. Mas eu falo para elas que isso daí é questão de hábito. Eu também falo da parte da criança, quando dá leite, não colocar açúcar dentro da mamadeira, tentar não colocar achocolatado também. Não enfiar chupeta... Mas aí, não tem como! Quando eu tenho oportunidade eu oriento, principalmente as crianças com relação a alimentação, bala, chiclete. Às vezes eu 'tô' conversando com a dona do armazém e as criança chega: “-Dá um real de bala!” Daí eu já aproveito: “-Você vai chupar bala agora ? Ta na hora do almoço!” Então eu aproveito as oportunidades que tem, principalmente quando tem crianças pequenas, porque as 'mãe' também não se "preocupa"; é bala, chiclete, acha que não precisa escovar porque é criança ainda; não usa pasta de dente. A gente orienta, quanto à escovação porque ela vai crescer, né? A gente vai orientando pra que faça a criança se acostumar com isso, porque se num acostuma agora num acostuma nunca mais, né? Então é mais com a criançada porque tem a oportunidade de trabalhar. Os pais não dão muito crédito pra gente. Mas os 'pequeninho' vão com a gente. Nossa, eles são 'bacana'! E aí a gente vai conseguindo. Um dia eles vão ser adultos, né?"

Dentre os que trabalham pouco ou não trabalham conteúdos em saúde bucal, vários motivos foram apresentados, como observado nos Discursos do Sujeito Coletivo apresentados a seguir.

DSC da ideia central A da questão 01 (Não, pois tem outros assuntos para trabalhar, outras prioridades ou falta de tempo para isso).
“Não, sinceramente é bem esporádico. Na minha opinião, eu acho que são muitos assuntos que a gente tem de falar e acaba que um ou outro vai sendo esquecido, vai 'sendo' de lado, e esse é um dos principais, eu acho. Geralmente a gente dá prioridade a outras coisas e não tem muito tempo de ficar fazendo este tipo de ação. É mais quando tá tudo normal, então você aproveita pra tá falando. Também porque nunca venho na mente de buscá um pouco mais esta área para tá passando. É uma coisa que a gente não liga muito, né? Assim, acho importante, faço, mas no diaa-dia e nas visitas às vezes acaba passando, né?"

Muitas vezes os ACS nem tocam no assunto saúde bucal, pois senão a população cobra a necessidade do profissional na Unidade de Saúde da Família.

DSC da ideia central D da questão 01 (Não, pois se toca no assunto, vem a cobrança em relação à necessidade de tratamento curativo).

"No dia-a-dia a gente não passa nada. Eu acho que já entra num outro assunto que é que o dentista aqui é muito, muito difícil. As pessoas procuram o serviço, procuram informar, mas a gente não tem onde passar, aonde recorrer e, por isso, a gente fica meio perdida. Porque quando a gente encaminha para fazer tratamento demora muito pra chamar eles - você sabe, né? Então se a gente começa a falar, eles acabam reclamando que tá demorando pra marcar. As pessoas têm dificuldades prá 'tá' indo 'tratando' no dentista. É fácil de falar: “-Vai!”...mas vai lá e nunca tem a vaga, né? Se a gente for encaminhar, não tem, porque prá mim 'pagá' é difícil.. E eles perguntam muito: “-Por que não tem? Por que PSF não tem dentista?” O povo quer muito, viu? Porque eles cobram bastante Então é complicado. Pelo fato de não ter, a gente nem toca no assunto porque daí já vem a cobrança, né?"

A dificuldade em encaminhar os casos com necessidade de tratamento curativo foi uma das barreiras citadas para os ACS não trabalharem conteúdos educativos em saúde bucal, fato esse verificado por meio do DSC da ideia central $\mathrm{H}$.

DSC da ideia central $\mathrm{H}$ da questão 01 (Às vezes. Tem dificuldade em trabalhar o assunto, pois não sabem o que fazer, para onde encaminhar os casos que necessitam de tratamento curativo, pois o acesso gratuito ao $\mathrm{CD}$ é difícil).

"Não muito, de vez em quando. A gente tem alguma dificuldade para trabalhar, porque, às vezes, a gente não sabe o que fazer, para onde mandar a pessoa quando tá com dor de dente. E parece que eles encontram bastante dificuldade, eles reclamam bastante: “-Eu vou em tal lugar, manda eu ir não sei aonde, volto não sei aonde e não tem aonde 
ir." Porque é muito difícil a gente 'tê' uma vaga lá embaixo com o dentista. Então a gente não tem nada o quê fazer. Mesmo que a gente encaminha 'prô' dentista, as mães vêm com reclamação que lá é fila, tem de ir às três, quatro horas da manhã prá 'tá' conseguindo uma vaga 'prô' dentista, então a maioria nem vai. E eles não vão acordar este horário porque eles acordam meio dia, uma hora. Então num 'vamô' 'falá' prá ela que elas têm que tá indo a cada três meses, a cada seis meses no dentista, porque isso é impossível. A gente tem essas 'dificuldade’ quando vai nas casas. Dessa forma, é muito pouca orientação que a gente tem e muito pouca orientação que a gente dá também.”

Os agentes têm de saber como tratar determinados assunto com a população, como observado pelo DSC da ideia central O.

DSC da ideia central O da questão 01 ( Tem de ter jeito para falar sobre o assunto, de acordo com a realidade deles).

"Tem que saber, quando a gente entra na visita, porque de repente se eu chegar: "-Viu, o seu dente...” - eu não sou dentista, né? Então fica chato pra mim. Então tem que ser daquele jeito, pegar aquele dado da pessoa. Eu tenho dificuldades, mas eu tenho um método, assim já. Porque como a gente já mora no bairro, na comunidade, se você começar muito a chegar e oi, oi e tal, elas pensam: - Não, não! Mora aqui, o que ela ta pensando que ela é? Entendeu? São bem assim. Aí a gente tem de chegar bem com jeitinho: - Olha, eu também moro aqui, eu também vou lá na Odontologia, entendeu, porque eu realmente estou fazendo tratamento lá com os estagiários da Odontologia. Eu também estou fazendo tratamento lá na Odontologia, eu não posso pagar! Eu explico para eles que não posso pagar, estou tratando lá, vou pôr prótese, estou com dor de cabeça pois falta dente na minha boca. Não é fácil, a gente trabalha aqui, então tem de começar bem assim: - A gente é igualzinha à você, nada pior ou melhor, somos todos iguais, só que tem de correr atrás. Olha, tem isso lá, faz inscrição - mas a fila é grande- mas a fila é grande mas você tá lá na fila, tem de ir tentando. Tem de começar por aí que aí você vai tirando uma grande barreira com o pessoal, sabe?"

Apesar de alguns ACS atestarem realizar educação em saúde, uma das dificuldades é quando a população não apresenta condições socioeconômicas para ter acesso à produtos de higiene bucal.

DSC da ideia central R da questão 01 (Trabalha, mas muitas vezes as pessoas não têm condições de seguir as orientações).

"Nóis' trabalha bastante na minha área, mas só que a gente não tem condições porque às vezes fala: “-Ah, não tenho escova.” Então o que você vai fazer? E as crianças 'minha' têm muito 'poblema' no dente. Muito dente podre... Logicamente não escova o dente todo o dia porque às vezes nem tem dinheiro pra comprar a pasta. Tem casa que a gente sabe que só tem a escova velha e, ou você leva uma escova nova, ou ela tem de escovar com aquela velha. Se você for falar de jogar fora, ela não vai ter nenhuma outra. Então é assim, você tem de encarar a realidade. Se não tem condições de comprar outra, tem de usar esta. Se você não tem outra aqui no posto prá dar, não adianta criticar. Ah, mas tá velha, tá horrível! Não adianta, porque ela não vai ter condição de comprar outra. Se você até mandar jogar, eles vão dizer:"Ùhh!" Porque é uma questão de bom senso, sabe? Você tem de saber lidar muito bem com isso. Tem de ser de acordo com a realidade deles dali. Por isso que eu falo, depende do jeito que você fala, eles vão aceitar esta orientação.”

O Quadro 2 apresenta a síntese das ideias centrais levantadas para a segunda questão e também suas respectivas frequências. Verificou-se que uma grande parcela dos ACS não recebeu nenhum tipo de curso de treinamento ou capacitação para realizar atividades educativas em saúde bucal. Por limitações de espaço, apresenta-se a ideia central B, com maior frequência citações entre os agentes.

DSC da ideia central B da questão 02 (Não. Recebem informações apenas quando os dentis-

Tabela 2. Síntese da idéias centrais e respectiva frequência de manifestações para a segunda questão: Você teve algum curso ou treinamento que lhe ensinou como fazer atividades educativas em Saúde Bucal?

\begin{tabular}{lrr}
\hline \multicolumn{1}{c}{ Idéias Centrais } & $\mathbf{n}$ & $\%$ \\
\hline A Não, nenhum da área da saúde. & 42 & 52,5 \\
B Não. Recebem informações apenas quando os dentistas da prefeitura realizam atividades na & 10 & 12,5 \\
USF ou quando participam com eles no Programa Dentinho Feliz nas escolas & 18 & 22,5 \\
C Sim, e foi bom. & 8 & 10 \\
D Sim, mas acha que foram poucos e rápidos. & 2 & 2,5 \\
E Já participou de cursos na Faculdade de Odontologia de Piracicaba & \\
\hline
\end{tabular}


tas da prefeitura realizam atividades na USF ou quando participam com eles no Programa Dentinho Feliz nas escolas).

"Não, nada. No primeiro dia de serviço tinham duas dentistas aqui nos dois períodos. Aí elas falaram prá gente como explicar 'prá' criança como escovar, como passar água na pasta, este tipo de coisa. Quando vêm os profissionais, aí a gente assiste à palestra, então alguma coisa a gente sabe. A gente tinha uma moça da saúde bucal que veio uma ou duas vezes dá palestra. Era lá da FOP e foi com a gente no CECAP uma ou duas vezes. Depois veio mais uma ou duas vezes dá palestra. Geralmente 'os dentista' vinham, conversava com a gente alguma coisa e... passavam: “-Óh, nós vamos tá fazendo tal coisa na escola e a gente só teve o Dentinho Feliz que eu participei. Porque aí faz com alguém da saúde bucal, que vai com a gente. A gente vai pra ajudar eles na escola. A gente aprende lá... Porque a gente aprendeu lá na escola as 'dentista' orientando as crianças; aí a gente vê e depois nas visitas a gente vai falando, né? "-Ah, precisa escovar o dente? Você tem escovinha?" Mais do que isso, eu não tive nenhuma orientação, nada. Então a gente não participou de um negócio específico com esse tipo de conteúdo. "Nós não somos treinadas, não existe assim uma coisa específica prá gente e não temos material pra tá trabalhando com eles com relação a isso."

\section{Discussão}

O presente trabalho teve o intuito de refletir sobre as práticas educativas em saúde bucal dos agentes comunitários de saúde na sua prática diária.

Verificou-se que a maioria dos agentes entrevistados era do gênero feminino, com idade entre 20 e 40 anos, tendo sua maioria o nível médio completo, ou seja, apresentaram características próximas ao perfil nacional desses profissionais ${ }^{13}$.

A profissão de ACS foi criada em 1991 e regulamentada por lei em $2002^{3}$. Para exercê-la, é necessário que o indivíduo possua o ensino fundamental completo. Observou-se, pelo presente estudo, que a maioria dos ACS entrevistados apresentava nível de escolaridade superior àquele exigido pela lei.

A ideia mais compartilhada entre os entrevistados foi a de que as atividades educativas eram realizadas de forma esporádica pelos ACS.

Em relação à análise dos dados qualitativos, verificou-se que, quando os ACS trabalham conteúdos de educação em saúde bucal, eles são mais voltados às gestantes, às mães e às crianças, prá- tica que se tem repetido em outras regiões do país, onde se observa uma predominância de ações organizadas para esses grupos, tal como o observado em outros estudos ${ }^{14-16}$. Aliás, essa priorização está de acordo com o preconizado pelo Ministério da Saúde, na Portaria 1.886 de 18 de dezembro de $1997^{17}$ a qual define, entre as atribuições básicas dos ACS, nas suas áreas territoriais de abrangência, a "realização de atividades de educação em saúde bucal na família, com ênfase no grupo infantil".

Quando os agentes estão capacitados a exercerem essas atividades, pode haver o aumento da consciência da população para o autocuidado em saúde bucal. Esse fato é corroborado pelo estudo de Frazão e Marques ${ }^{7}$, os quais verificaram mudanças significativas nos conhecimentos de saúde bucal por parte de mulheres e de mães da área de atuação dos agentes, que foram capacitados a realizar Educação em Saúde junto à comunidade.

Entretanto, como observado no presente estudo, muitos agentes não realizam atividades de educação em saúde bucal, ou fazem de forma esporádica, pelo fato de não terem sido capacitados para isso, evidenciado por meio das ideias centrais B e H. Para Rodrigues et al. ${ }^{16}$, a desenvoltura dos ACSs para abordarem temas em saúde bucal deve-se aos processos de educação permanente, nos quais os agentes estão envolvidos. Dessa forma, destaca-se a importância da equipe de Saúde e do gestor municipal em proporcionarem esse tipo de atividade aos ACSs.

De uma forma geral, os ACS do presente estudo atestaram que realizam as atividades educativas em saúde bucal sob a forma de orientações, cujos conteúdos se voltam à escovação dentária e aos cuidados com a ingestão de carboidratos fermentáveis, corroborando os achados do estudo de Koyashiki et al. ${ }^{18}$, no qual as ações em educação em saúde bucal desenvolvidos pelos ACSs visavam, por meio da transmissão de informações, a mudança de comportamentos individuais e a incorporação de hábitos saudáveis.

Um ponto crítico apontado pelos agentes e verificado no DSC H da questão 01 foi a dificuldade dos ACSs em encontrarem respostas às demandas curativas da população, pois as Unidades de Saúde da Família do município não apresentavam, até então, equipes de saúde bucal e a fila para tratamento nas Unidades Básicas de Saúde que contavam com um profissional era extensa ou haviam outros problemas que dificultavam seu acesso. Ressalta-se aqui a dificuldade dos ACS em realizarem atividades educativas desvinculadas de uma prática integral de aten- 
ção à Saúde, entendida como um conjunto articulado e contínuo das ações e dos serviços preventivos e curativos, individuais e coletivos, exigidos para cada caso, em todos os níveis de complexidade do sistema ${ }^{19}$. Portanto, os agentes percebem que seus discursos educativos em saúde bucal muitas vezes perdem sua força e legitimidade quando não estão integrados a um sistema de suporte e promotor da saúde, que procura promover a equidade e diminuir as iniquidades.

Esse fato também foi observado nos discursos do ACSs do estudo de Rodrigues et al. ${ }^{16}$, no Programa de Saúde da Família em Alagoinhas Bahia, os quais discorrem sobre os limites das ações de educação em saúde quando estão não incorporadas a condutas terapêuticas integrais.

Corroborando esse ponto de vista, Koyashiki et al. ${ }^{18}$ afirmam que "mesmo reconhecendo o ACS como recurso importante do acesso aos serviços odontológicos, sabe-se que, para a resolução dos problemas relacionados à demanda, fazse necessário garantir a oferta de condições satisfatórias de trabalho bem como uma infraestrutura mínima e adequada”.

Solla et al. ${ }^{20}$ alertam que essas dificuldades de se trabalhar em um sistema integral de atenção à saúde pode resultar na perda da legitimidade do $\mathrm{ACS}$, frente à comunidade, e o desestímulo do profissional para o desempenho de suas ações.

Portanto, segundo Schall \& Stuchiner ${ }^{21}$, uma das propostas para se melhorar essas práticas seria trabalhar-se uma educação em saúde ampliada, caracterizada por propostas pedagógicas libertadoras, comprometidas com o desenvolvimento da solidariedade e da cidadania, orientando-se para ações cuja essência está na melhoria da qualidade de vida e na promoção do homem.

Apenas duas agentes declararam realizar orientações relativas à prevenção do câncer bucal. Em contrapartida, verifica-se que esse tipo de atividade é amplamente realizado por agentes em alguns municípios, como é o caso de Alagoinhas, $\mathrm{BA}$, em que os profissionais foram capacitados para difundir orientações sobre o autoexame bucal para a identificação de lesões e para o rastreamento de lesões cancerizáveis pelos próprios $\mathrm{ACS}^{22}$. Percebe-se, assim, que, quando capacitados, esses profissionais podem exercer uma importante função na prevenção do câncer bucal.

Em relação à segunda questão, percebeu-se uma alta frequência de ideias centrais referentes à não capacitação dos ACS para exercerem atividades educativas em saúde bucal.

Esse fato também foi observado em outros estudos, como o de Moura et al. ${ }^{15}$, em pequenos municípios do estado do Piauí, onde se observou que a maioria $(79,8 \%)$ dos agentes entrevistados não foi capacitada e que 59,6\% não assistiram a nenhum tipo de palestra educativa sobre Saúde bucal. Entretanto, mais da metade realizava essas atividades na prática diária. $\mathrm{O}$ mesmo fato também foi verificado por Levy et al. ${ }^{14}$ no município de Bauru, SP e Koyashiki et al. ${ }^{18}$ em Londrina, PR. Portanto, ainda que se pese a importância dos agentes em promoverem a saúde bucal da população sob seus cuidados, esse trabalho torna-se comprometido se os mesmos não estiverem adequadamente treinados e capacitados para exercerem essas atividades de forma satisfatória.

Diferentemente de outros municípios que já apresentam equipes de Saúde bucal incorporadas à estratégia da Saúde da Família, o município de Piracicaba, até o momento da finalização da presente pesquisa, não apresentava cirurgiões-dentistas trabalhando nas equipes. Assim sendo, a única forma de contato das ACS com conteúdos em Saúde bucal eram as capacitações oferecidas pela Coordenação da Atenção Básica, ou mesmo, dentro das próprias USF, a partir de outros profissionais, embora não graduados em Odontologia. Em municípios onde já existem equipes de Saúde bucal incorporadas, observa-se que as agentes apresentam melhores capacidades e desenvoltura para desenvolver temas em Saúde bucal com a comunidade, pois aprendem continuamente com o cirurgião-dentista da equipe ${ }^{16}$.

Concluindo, os resultados obtidos sugerem a necessidade dos ACS repensarem a forma como vêm desenvolvendo suas práticas educativas em saúde bucal, a fim de favorecerem a construção da cidadania plena pelos indivíduos e não só sua adequação às normas de bem-viver ditadas pela ciência Odontológica. Entretanto, para que isso se torne realidade, é imprescindível que o apoio do gestor local na capacitação e formação continuada desses profissionais e respectivas equipes. Dessa forma, recomenda-se que os resultados da presente pesquisa sirvam para o treinamento tanto das equipes como para discussão entre gerentes e gestores, uma vez que servem de espelho e ponto de partida para trabalhos de capacitação e processos de tomada de decisão.

\section{Colaboradores}

FL Mialhe, F Lefèvre e AMC Lefèvre participaram igualmente de todas as etapas de elaboração do artigo. 


\section{Agradecimentos}

Aos agentes comunitários de saúde e à Fundação de Apoio à Pesquisa do Estado de São Paulo (FAPESP) pelo auxílio à pesquisa.

\section{Referências}

1. Mendes EV. A evolução histórica da atenção primária à saúde no Brasil. In: Mendes EV. A Atenção Primária à Saúde no SUS. Fortaleza: Escola de Saúde Pública do Ceará; 2002.

2. Tomaz JBC. O agente comunitário de saúde não deve ser um "super herói". Interface Comun Saúde Educ 2002; 6(10):75-94.

3. Brasil. Ministério da Saúde (MS). Política Nacional de Atenção Básica. 4. ed. Brasília; Ministério da Saúde; 2007.

4. Brasil. Ministério da Saúde (MS). Portaria MS/GM n.1.444 de 28 de dezembro de 2000. Estabelece incentivo financeiro para a reorganização da atenção básica à saúde da família prestada nos municípios por meio do Programa de Saúde da Família. Diário Oficial da União 2000; 29 dez.

5. Souza DS, Caminha JAN, Ferreira MA, Tomita NE, Narvai PC, Gevaerd SP, Mendes WB. A inserção da Saúde Bucal no PSF. Rev Bras Odont Saúde Coletiva 2001; 2(2):7-29.

6. Brasil. Ministério da Saúde (MS). Diretrizes da política nacional de saúde bucal, 2004. [acessado 2008 jul 25]. Disponível em: http://conselho.saude.gov.br/ web_comissoes/cisb/doc/politica_nacional.pdf

7. Frazão P, Marques, DSC. Influência de agentes comunitários de saúde na percepção de mulheres e mães sobre conhecimentos de saúde bucal. Cien Saude Colet 2006; 11(1): 131-144.

8. Trapé CA, Soares CB. Educative practice of community health agents. Rev Latino-am. Enfermagem 2007; 15(1):141-149.

9. Instituto Brasileiro de Geografia e Estatística (IBGE). Banco de dados. Cidades [acesso 2008 ago 2]. Disponível em:http://www.ibge.gov.br/home/ 2007

10. Lefèvre F, Lefèvre AMC. O discurso do sujeito coletivo: um novo enfoque em pesquisa qualitativa (desdobramentos). Caxias do Sul: EDUCS; 2003.

11. Lefèvre F, Lefèvre AMC. O sujeito coletivo que fala. Interface Comun Saúde Educ 2006; 10(20):1-8.

12. Lefèvre F, Lefèvre AMC. Depoimentos e discursos: uma proposta de análise em pesquisa social. Brasília: Editora Liber; 2005.

13. Brasil. Ministério da Saúde. Saúde da Família chegará a 140 milhões, 2008 [acessado 2008 ago 06]. Disponível em: http://www.saude.gov.br

14. Levy FM, Matos PES, Tomita NE. Programa de agentes comunitários de saúde: a percepção de usuários e trabalhadores da saúde. Cad Saude Publica 2004; 20(1):197-203.
15. Moura MS, Carvalho CJ, Amorin JTC, Marques MFSS, Moura LFAD, Mendes RF. Perfil e práticas de saúde bucal do agente comunitário de saúde em municípios piauienses de pequeno porte. Cien Saude Colet [periódico na Internet]. 2007 [acessado 2008 jul 25]; 15(1): Disponível em: http://www.scielosp. org/scielo.php?pid=S1413-81232010000700061\& script=sci_arttext

16. Rodrigues AAAO, Santos AM, Assis MMA. Agentes comunitários de saúde: sujeito da prática em saúde bucal em Alagoinhas. Cien Saude Colet [periódico na Internet]. 2007 [acessado 2008 jul 23];15(3):907915. Disponível em: http://www.scielo.br/scielo.php ?script=sci_arttext\&pid=S1413-81232010000300034

17. Brasil. Ministério da Saúde. Portaria no 1886/GM de 1997. Aprova as Normas e Diretrizes do Programa de Agentes Comunitários de Saúde e Programa de Saúde da Família. Diário Oficial da União 1997; $18 \mathrm{dez}$.

18. Koyashiki GAK, Alves-Souza RA, Garanhani ML. O trabalho em saúde bucal do agente comunitário de saúde em unidades de saúde da família. Cien Saude Colet [periódico na Internet]. 2006 [acessado 2008 jul 23]; 13(4):1343-1354. Disponível em: http://www. scielo.br/scielo.php?pid=S1413-81232008000400032 \&script=sci_arttext

19. Machado MFAS, Monteiro EMLM, Queiroz DT, Cunha VNF, Teixeira BMG. Integralidade, formação de saúde, educação em saúde e as propostas do SUS- uma revisão conceitual. Cien Saude Colet 2007; 12(2):335-342

20. Solla JJSP, Medina MG, Dantas MBP. O PACS na Bahia: avaliação do trabalho dos agentes comunitários de saúde. Saúde Debate 1996; 51:4-15.

21. Shall VT, Stuchiner M. Educação em saúde: novas perspectivas. Cad Saude Publica 1999; 2(15):4-5.

22. Araújo CT. Confiabilidade do exame bucal realizado por agentes comunitários de saúde no rastreamento de condições, lesões cancerizáveis e câncer bucal no município de Alagoinhas [monografia]. Feira de Santana: UFS/FO; 2001.

Artigo apresentado em 13/03/2009

Aprovado em 24/06/2009

Versão final apresentada em 29/06/2009 